\title{
Monitoring Sugarcane Growth Phases Based on Satellite Image Analysis (A Case Study in Indramayu and its Surrounding, West Java, Indonesia)
}

\author{
Tri Muji Susantoro", 2*, Ketut Wikantika1,3,4, Agung Budi Harto', ${ }^{1,}$ Deni Suwardi1, 3 \\ ${ }^{1}$ Center for Remote Sensing, Bandung Institute of Technology, Bandung, Indonesia \\ ${ }^{2}$ Research and Development Center for Oil and Gas Technology "LEMIGAS", Ministry of Energy and Mineral Resources, Jakarta, \\ Indonesia \\ ${ }^{3}$ Faculty of Earth Sciences and Technology, Bandung Institute of Technology, Bandung, Indonesia \\ ${ }^{4}$ ForMIND Institute (Indonesian Young Researcher Forum), Bandung, Indonesia
}

\section{ARTICLE INFO}

\section{Article history:}

Received February 10, 2017

Received in revised form September 20, 2018

Accepted January 30, 2019

\section{KEYWORDS:}

Sugarcane,

Landsat 8,

Growth Phases,

NDVI,

ENDVI

\begin{abstract}
This study is intended to examine the growing phases and the harvest of sugarcane crops. The growing phases is analyzed with remote sensing approaches. The remote sensing data employed is Landsat 8 . The vegetation indices of Normalized Difference Vegetation Index (NDVI) and Enhanced Normalized Difference Vegetation Index (ENDVI) are employed to analyze the growing phases and the harvest of sugarcane crops. Field survey was conducted in March and August 2017. The research results shows that March is the peak of the third phase (Stem elonging phase or grand growth phase), the period from May to July is the fourth phase (maturing or ripening phase), and the period from August to October is the peak of harvest. In January, the sugarcane crops begin to grow and some sugarcane crops enter the third phase again. The research results also found the sugarcane plants that do not grow well near the oil and gas field. This condition is estimated due as the impact of hydrocarbon microseepage. The benefit of this research is to identify the sugarcane growth cycle and harvest. Having knowing this, it will be easier to plan the seed development and crops transport.
\end{abstract}

\section{Introduction}

Sugarcane represents an important crop for food and fuels in tropical countries (Pongpat et al. 2017). It also grows in subtropical countries (Obando et al. 2017; Silalertruksa et al. 2017). The largest sugarcane producer is Brazil, followed by India, China, Thailand, and Pakistan (FAO 2014; Zhou et al. 2015). Indonesia is one of the world's sugar-producing countries. Where in 1984-1985 Indonesia was a sugar self-sufficient country. However, it failed to be maintained due to increasing population and financial crisis (Fadilah and Sumardjo 2011).

Indonesia targets to achieve the sugar selfsufficiency in 2014 (Fadilah and Sumardjo 2011; Khuluq and Hamida 2014). The land extensification approach to increase the sugar production is difficult because of land constraints (Khuluq and Hamida 2014). Intensification of sugarcane plantations is

\footnotetext{
* Corresponding Author

E-mail Address: trimuji_s@yahoo.com
}

possible to do in Indonesia (Suhardi et al. 1999). This is done by providing convenience to farmers in the provision of sugarcane seeds, fertilizers, pesticides, cutting and transport costs and bank credit (Fadilah and Sumardjo 2011). Another effort that supports agricultural intensification is physiological engineering of sugarcane through evaluation and optimization of the crop growth phase. By this approach, it is expected that sugarcane will result in optimum productivity and yield (Khuluq and Hamida 2014).

Sugarcane production is a function of crop, soil, climate, and farming practices carried out by farmers (Pramuhadi 2009; 2010). The ideal conditions to produce a maximum sugarcane production requires superior sugarcane varieties, optimum soil conditions and climate for sugarcane growth with adequate water and fertilizer requirements (Pramuhadi 2010). The ideal conditions cannot be done in all cultivated lands. But the use of quality seeds in the sense of superior, pure, healthy and sufficiently aged varieties, sufficient quantities and available on time, is the absolute 
requirement for sugarcane cultivation. Such condition is a must if the "commitment" to accelerate the desired increase of national sugar production will be achieved (Rahmad 2012).

Sugarcane (Saccharum officinarum) in Indonesia is the raw material for sugar industry only. It is different from other countries where the beet can be used as an alternative such as fuels. Sugarcane farming is applied in irrigated and non-irrigated land. Usually, the farms are categorized as plant cane (newly planted) or ratoon cane (second or more generation). Sugarcane can be harvested after 9 to 12 months. In Java, the optimal time to start sugarcane planting is from May to August, but the actual planting may take place until December due to land availability (Ismoyowati 2004). Sugarcane crop is a plant which life cycle consists of 4 phases, namely germination phase during 0 to $1^{\text {st }}$ month after planting, tillering phase (fast growth) during the $1^{\text {st }}$ to $3^{\text {rd }}$ months after planting, stem elongation phase (grand growth phase) during the $3^{\text {rd }}$ to $9^{\text {th }}$ months after planting and maturity or ripening phase during the $10^{\text {th }}$ to $12^{\text {th }}$ months after planting (Rahman et al. 2004; Pramuhadi 2010).

Remote sensing technology is widely used in environmental and agriculture research. The beneficial use of remote sensing, it can play a role in providing information about crop type, conditions and yield from field level to extended geographic areas regional countries and continents (Junior et al. 2014). Remote sensing provides an effective method due to its unique capabilities in terms of its spectral, temporal, and spatial resolutions (Xavier et al. 2006). Spectral information is well related with agronomic variables and can be used for crop monitoring and yield forecasting (Simoes et al. 2005). Multitemporal remote sensing has been widely applied for land cover classification (Bock et al. 2005) and variation that occurs over time (change detection) and particularly useful for near real-time information collection at a regional scale (Junior et al. 2014). The spatial resolutions are divided into low, medium, and high resolution. The used of it depends on the of the analysis to be done (Junior et al. 2014).

Studies on sugarcane using vegetation index of remote sensing data are important because this trait correlates with growth phases, disease detection, and yield prediction (Apan et al. 2004; Xavier et al. 2006; Rudorff et al. 2010). In this study, sugarcane growth is monitored with remote sensing data of Landsat $8 \mathrm{OLI} /$ TIRS. The previous research showed Landsat images proved to be potential for sugarcane monitoring in the south and central Brazil (Rudolff et al. 2010). The main purpose of this study is to examine the growing phases and the harvest of sugarcane crops. The sugarcane growth is analyzed with vegetation indices. The vegetation indices represent a single value for converting the reflectance spectrum to measure the vegetation properties (Robert et al. 2011). Vegetation indices are constructed from reflectance measurements in two or more wavelengths, mainly from visible to near infrared to analyze the specific characteristics of vegetation, such as total leaf areas, pigments (chlorophyll, carotenoids, anthocyanins), plant structure materials, and water content (Salas and Henebry 2014). The vegetation indices primarily accentuate the aspects of density, such as biomass, leaf area index (LAI) and chlorophyll concentration (Danoedoro 2012).

\section{Materials and Methods}

\subsection{Study Area}

The study was conducted in Jatitujuh sugarcane plantation. Jatitujuh sugarcane lies in Indramayu and Majalengka Regencies, West Java, Indonesia. The location is around $145 \mathrm{~km}$ from Jakarta, Indonesia. Geographically, it is situated in 1080 5' $^{\prime} 47^{\prime \prime}$ to 1080 16 '38"E longitudes and 6031 '50" to 60 37'32" S latitudes on about 21-45 meter above sea level. The study area is one of the largest sugarcane plantations in West Java. In this study, the location is limited to the sugarcane plantation of PG Jatitujuh unit only which is under PT PG Rajawali II. In the middle of sugarcane plantation also contains oil and gas field active that operated by Pertamina. Several wells have been drilled since 1979 (Pertamina 1994).

The sugarcane plantation in Majalengka is 5,673.04 $\mathrm{Ha}$, while in Indramayu is $6,248.52 \mathrm{Ha}$. PG Jatitujuh has a sugar mill located amidst the plantation. Since 2007 , the sugar mill also received the farmers's sugarcane crops from around the mill site which reach 1,263 Ha. The sugar mill is located in sumber village, Jatitujuh sub-district (Fadilah and Sumardjo 2011). In terms of climate, in general, there are two seasons, the rainy season occurs in October-March while dry season in April-September (Darojati et al. 2015). The location of the study can be seen in Figure 1.

\subsection{Data Processing}

This study was conducted using six series of Landsat 8 OLI/TIRS images (March 17, 2015; May 20, 2015; July 7, 2015; August 10, 2016; October 29, 2016; and January 1, 2017). Landsat 8 OLI/TIRS images were acquired from the free global Landsat data (http:// earthexplorer.usgs.gov/). The selected images were all with minimum cloud and covered the study area.

The Landsat 8 OLI/TIRS images were processed through radiometric correction, geometric correction, 


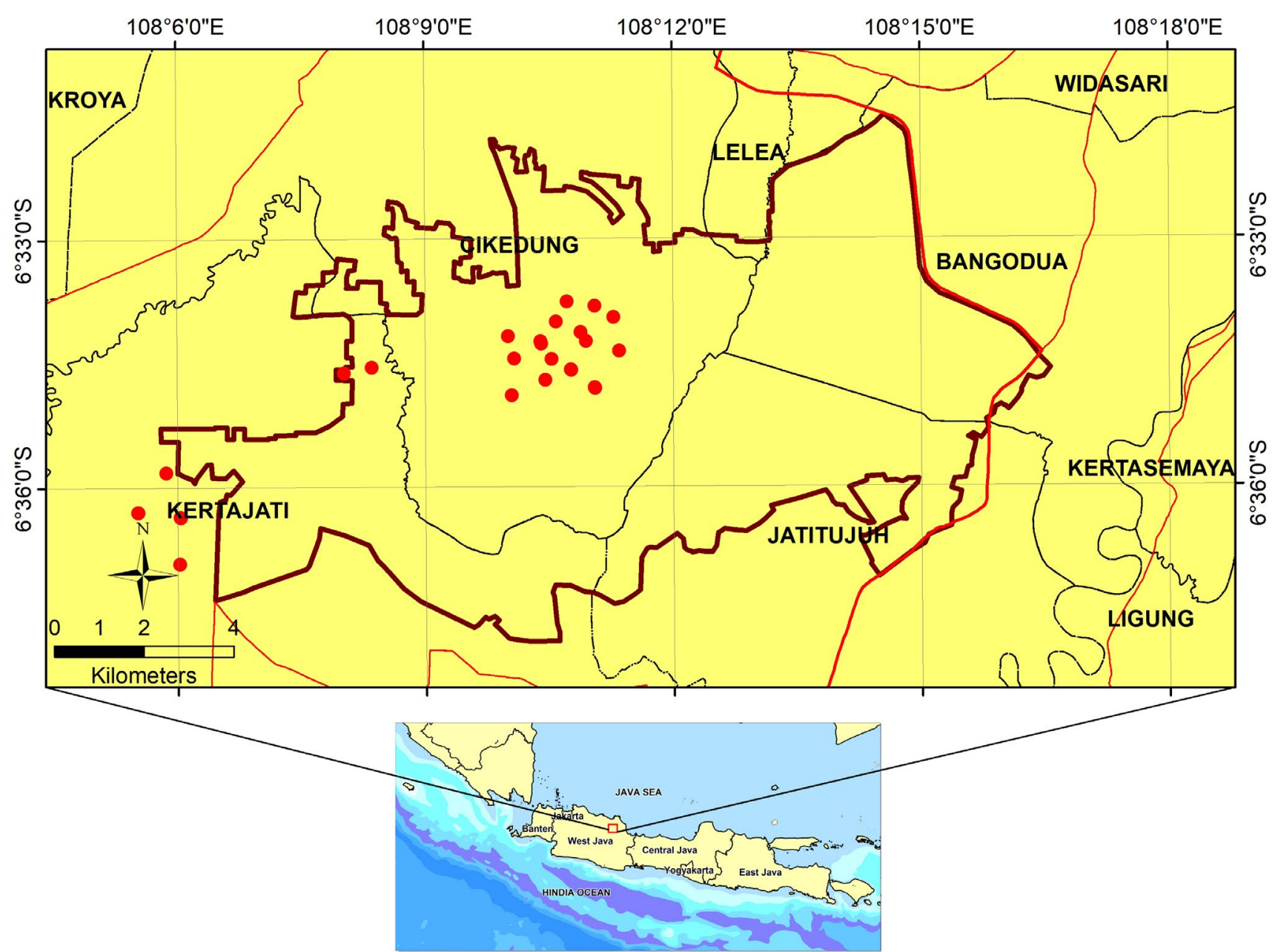

Figure 1. Study area presented by brown lines with subset of Java Island in north part overlaid with oil and gas wells in red dots

and vegetation indices ratio. The radiometric correction is a multi-stage process from radiometric calibration to atmospheric correction. It is important to increase the quality of correlations between spectral data and surface, especially to estimate the vegetation index (Pereira and Casaroli 2016). The geometric correction is a process transforming any pixel of the Landsat 8 OLI/TIRS images into a new coordinate system in a specified map project. The images were thus rectified using the Universal Transverse Mercator (UTM) WGS 84 projection Zona 49 South following the cubic convolution technique. The root mean squares error (RMSE) of the geometric correction of images was 0.344795 or it means the possibility of spatial displacement is 10.34 meters.

\subsection{Growth Phase Interpretation}

The growth phase and harvest in sugarcane plantation are interpretating with Normalized
Difference Vegetation Index (NDVI) (Rouse et al. 1974) and Enhanced Normalized Difference Vegetation Index (ENDVI) (Maxmax 2015). NDVI is the standard algorithm employed to quantify and map the spatial distribution of green vegetation (Brantley et al. 2011). It is the most popular vegetation index that is directly related to the photosynthetic capacity and the ability to absorb energy in the vascular plants (Tucker et al. 1985). Similar to NDVI, ENDVI is an indicator of live green vegetation and can be used for crops in all growth stages (Precisionmapper 2017). The formula of this vegetation index is defined as follows:

$$
N D V I=\frac{(\text { onir- }-\dot{r e d})}{(\text { onir }+\rho r e d)}
$$

Where $\rho n i r$ is near infrared band reflectance and $\rho r e d$ is red band reflectance. 


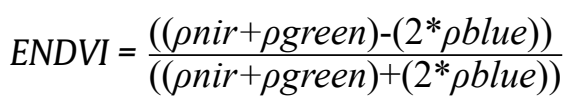

Where $\rho$ green is green band reflectance and $\rho$ blue is blue band reflectance.

NDVI and ENDVI values are represented as a ratio ranging in value from -1 to 1 . NDVI values in practice, negative values represent water, around of zero values represent bare soil and over than 0.6 values represent dense green vegetation (Chimnarong et al. 2012). Similar to NDVI, ENDVI values between -1 to 0 represent nonvegetation and over than 0.7 values represent dense vegetation. The growth phase and harvest interpretation in this work based on NDVI and ENDVI values.

NDVI and ENDVI values are divided into 7 classes. This is done to observe of sugarcane growth phase. The sugarcane at the beginning of planting are still dominated by the soil. The vegetation index values in this phase are very low. In the second phase, the vegetation index values begin to increase but still mixed with the soil spectral so that the value is still low. In the third phase, the vegetation index values continue to increase and will reach the peak values. In the fourth phase of vegetation index values decreased. this condition indicates the sugar cane plant is ready to be harvested. In post-harvest vegetation index values become very low. This condition occurs continuously so it is useful for monitoring sugarcane crops.

\subsection{Field Survey}

Field survey is a necessary aspect of remote sensing. Field data are needed to describe the present condition in an area, identify the locations of habitats in imagery and to provide an independent evaluation of the results of vegetation index (Congalton 1991). In this study, the field surveys were conducted twice, in March and August 2017. Generally, field surveys were conducted to observe sugar mill activities and sugarcane conditions. The observations of sugar mill activities were undertaken to assess their relationship with harvest periods. The observation of sugarcane cultivation condition is done to examine the relationship with its growth phase. The results are used for vegetation index assessment.

Field surveys were also conducted for validation the growth phase and harvest of sugarcane crops as Landsat $8 \mathrm{OLI} / \mathrm{TIRS}$ interpretation results. A field survey in March was conducted to ensure that at the time sugarcane was at the peak of the third phase. A field survey in August was conducted to ensure that at the time was the peak of the harvest.

\subsection{Analysis}

Analysis of the growth phase were presented in map, histogram and described descriptively. Identification of the growth phase based on field survey. The analysis process is conducted by correlating the vegetation index value with the growth phase of sugarcane. At the same location will show a normal distribution pattern on the vegetation index value. Low vegetation index values occur at the germination phase of sugarcane crops. This occurs either on the cane (newly planted) or ratoon cane (second or more generation) plant and then increase to the third phase and decrease when the fourth phase and very low at post-harvest. This cycle continues and can be monitored with Landsat 8 OIL/TIRS images.

In this study, we tried to correlate between NDVI and ENDVI using 1733 samples. The samples are taken out continuously cross the study area with the westeast direction. The correlation analysis between NDVI and ENDVI is done by the coefficient of determination $\left(\mathrm{R}^{2}\right)$ method.

\section{Results}

\subsection{Normalized Difference Vegetation Index}

The NDVI results indicated that in March the sugarcane crops are dominated by the stem elongating phase or the third phase. In this month the value of NDVI is dominated between 0.7 to 1 . In May they are still dominated by the third phase with the NDVI values from 0.7 to 1 , but in this month some sugarcanes are starting the maturity phase (fourth phase). This is indicated by the reduced NDVI values ranging from 0.7 to 1 while partly the NDVI values are changing from 0.55 to 0.7. This occurs because in the fourth phase, the leaf chlorophyll contents are decreasing and the leaves changes to dry and yellowish (Mochtar 1994). In July, the NDVI values still dominate from 0.7 to 1 , but some NDVI values are decreasing from 0.55 to 0.7 . It means that the sugarcane crops are at the peak of the third phase. In this month, some sugarcane crops are starting to be harvested. This is indicated by the NDVI values which are increasing from 0 to 0.35 .

In August, the NDVI values ranging from 0.7 to 1 and the NDVI values of 0.55 to 0.7 are becoming dominant. This shows that almost all sugarcane crops have moved to the fourth phase and this is the peak of the harvest season. In August, the sugarcane that have been harvested, in July are starting growing as the first phase and second phase. This is shown by the 
NDVI values from 0.25 to 0.35 and 0.35 to 0.45 which are spread widely within the area of $15.35 \mathrm{sq} \mathrm{km}$ and $14.20 \mathrm{sq} \mathrm{km}$. In October, the first and second phases start moving to the third phase. The third phase is the longest growing phase of sugarcane crops, which starts from the $3^{\text {rd }}$ to $9^{\text {th }}$ months after planting (Rahman et al. 2004; Ismoyowati 2004; Pramuhadi 2010).

In January, the sugarcane crops are starting the third phase, as shown from the NDVI values from 0.55 to 7 in the area about $50.12 \mathrm{sq} \mathrm{km}$. In this month, the NDVI values are also seen ranging from 0.25 to 0.35 and from 0.35 to 0.45 which are still relatively high, in the area about $3.05 \mathrm{sq} \mathrm{km}$ and $8.82 \mathrm{sq} \mathrm{km}$ respectively. This is thought that the planted sugarcanes are in the final stage of harvest. The chart of NDVI values in March, May, July, October, and January can be seen in Figure 2. The NDVI map also can be seen in Figure 3.

\subsection{Enhanced Normalized Difference Vegetation Index}

Based on the ENDVI result shows that in March, the sugarcane crop in the stem elonging phase. The area of ENDVI high values ( 0.7 to 1 ) is $92.31 \mathrm{sq} \mathrm{km}$. This shows that sugar cane plant is at the peak of elongation phase of the stem (third phase). In this phase, the leaves look lush, fresh, and green. In May and July, sugarcane crop begins to move the fourth phase. ENDVI values in May and July was dominated by 0.6 to 0.7 which indicated that sugarcane crop started to move the fourth phase. In this month sugarcane harvest is started.

In August showed that most sugarcane crops have been harvested and 0.5 to 0.6 of ENDVI values becoming dominant. The values indicated that almost all of the sugarcane crop has moved the fourth phase. In this month is the peak of harvest. In October the harvest period is still ongoing and some of the lands begin to be replanted. In January, ENDVI results dominated by a value of 0.6 to 1 , it is showed some plants began to move the beginning of the third phase. The ENDVI value chart in March, May, July, August, October, and January can be seen in Figure 4. The ENDVI map can be seen in Figure 5.

The survey results showed that in the south of the oil and gas field there are sugarcane plants that do not grow well. The number of clumps of sugarcane crops ranges from 2 to 7 and the trees height between 1 meter and 1.7 meter includes the tops of the leaves. This is different from elsewhere, where the clump of sugarcane can reach 11 to 20 pieces. This condition is thought to be an anomaly of vegetation. A survey in August showed that the sugarcane plant in the south of the oil and gas field could not be harvested and suffered death. The photos of sugarcane condition can be seen in Figure 6.

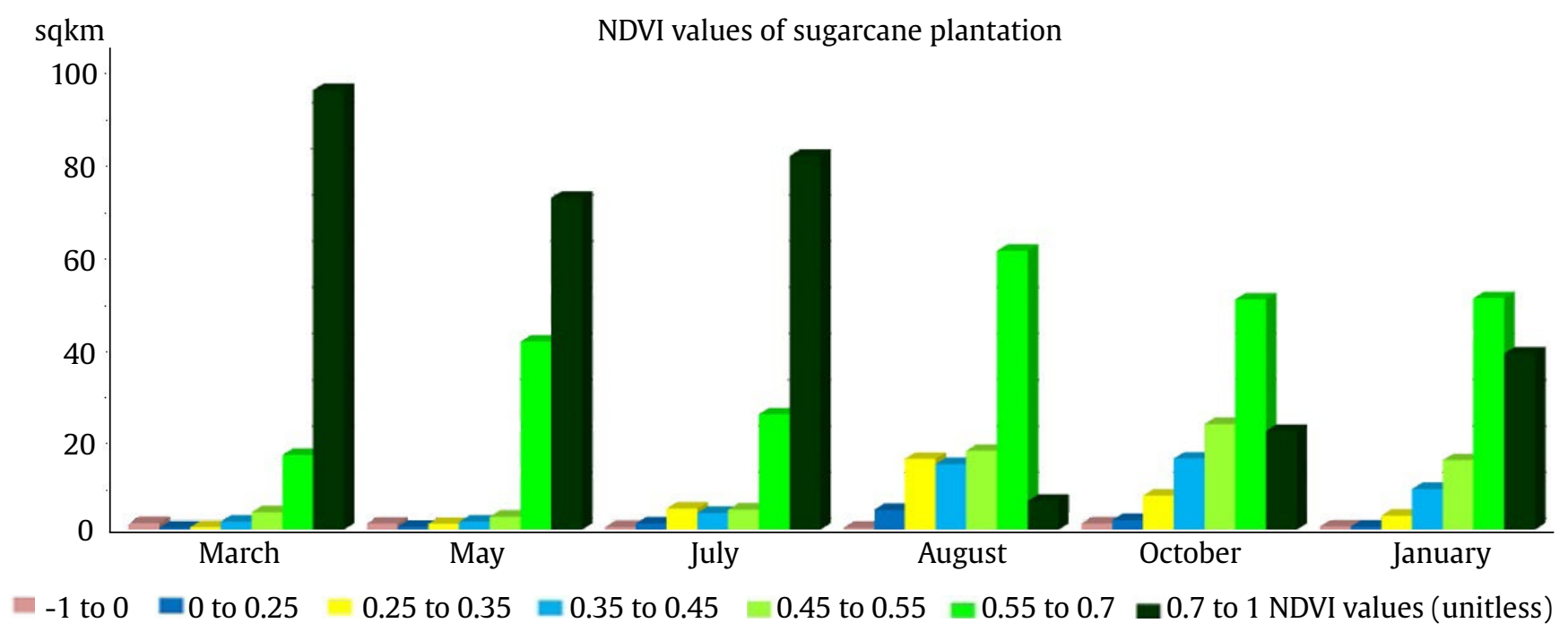

Figure 2. Chart of sugarcane area based on NDVI values. Based on the chart, it can be analyzed that March is the peak of the third phase of sugarcane crops and the peak of the harvest is from August to October 


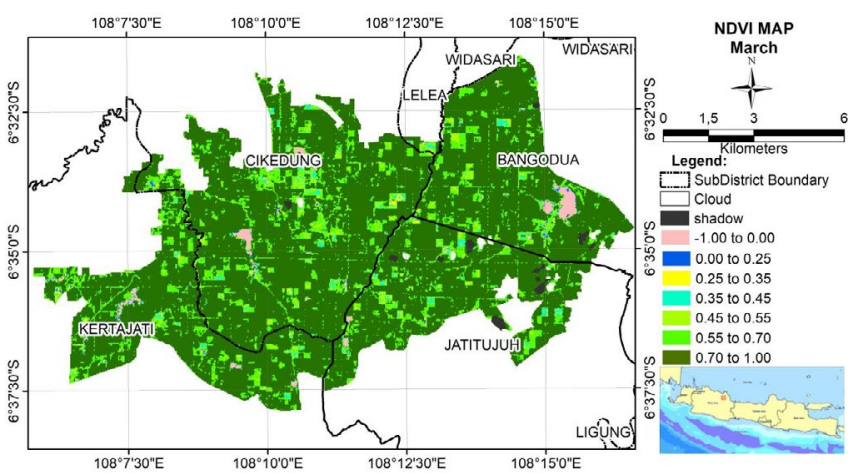

a. In March the NDVI results showed the dominant values in the third phase
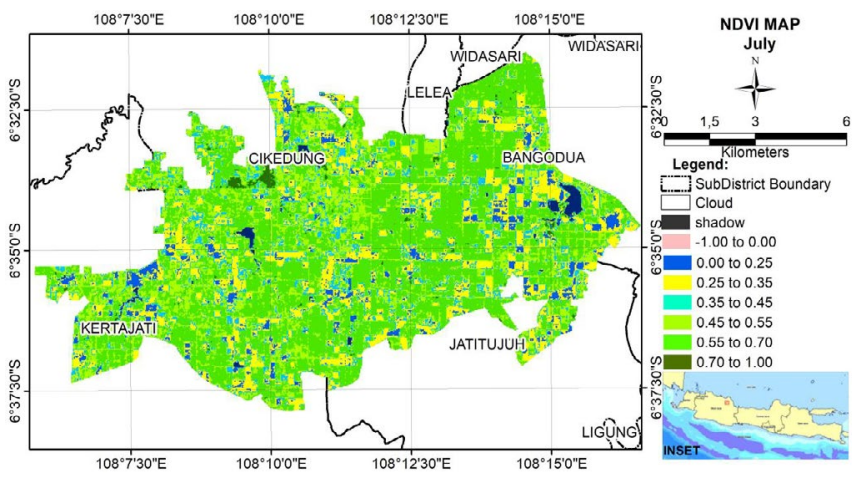

c. In July the NDVI results showed the dominant values in the third phase, but some sugarcane crops moved to the fourth phase and some started to harvest
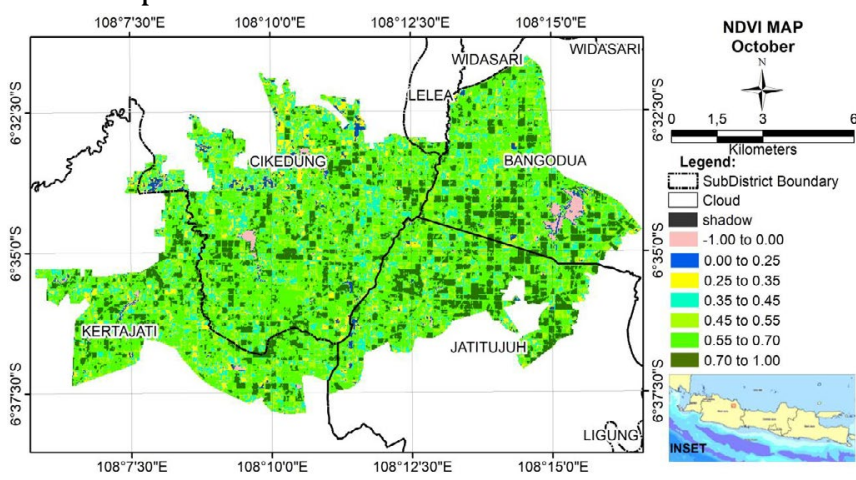

e. In October the NDVI results showed the land began to be planted and a small part of sugarcane crops started to move to the third phase

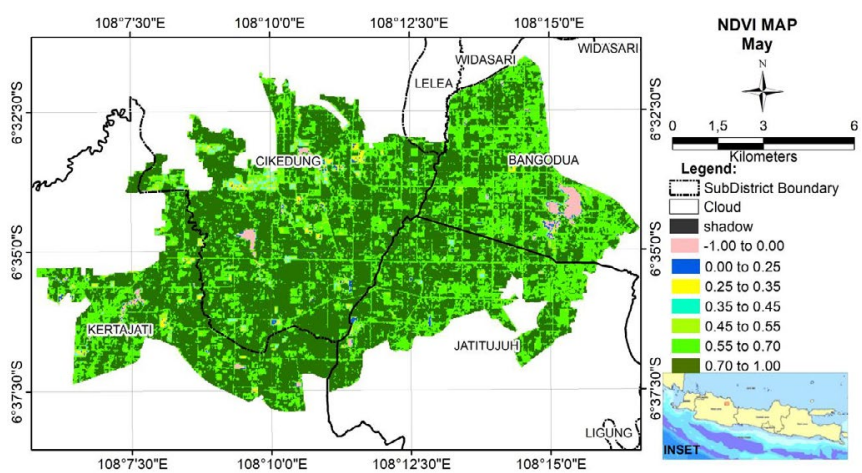

b. In May the NDVI results showed the dominant values is in the third phase, but some sugarcane crops started moving to the fourth phase

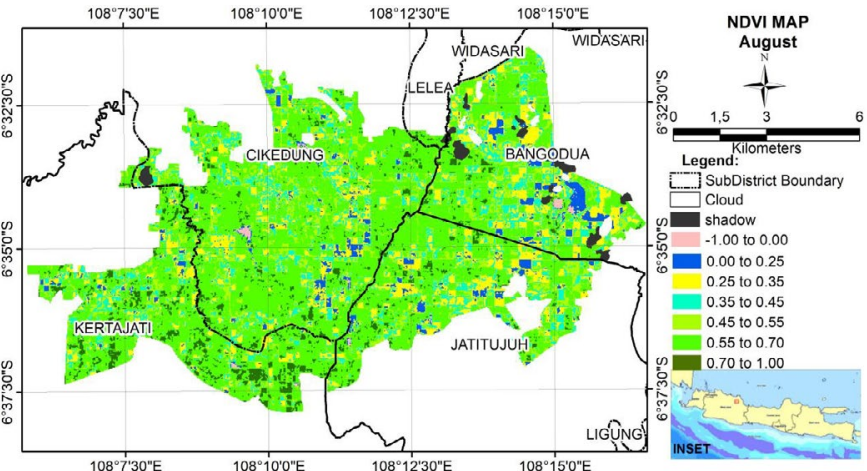

d. In August the NDVI results in showed the dominant values is in the fourth phase and the peak of harvest

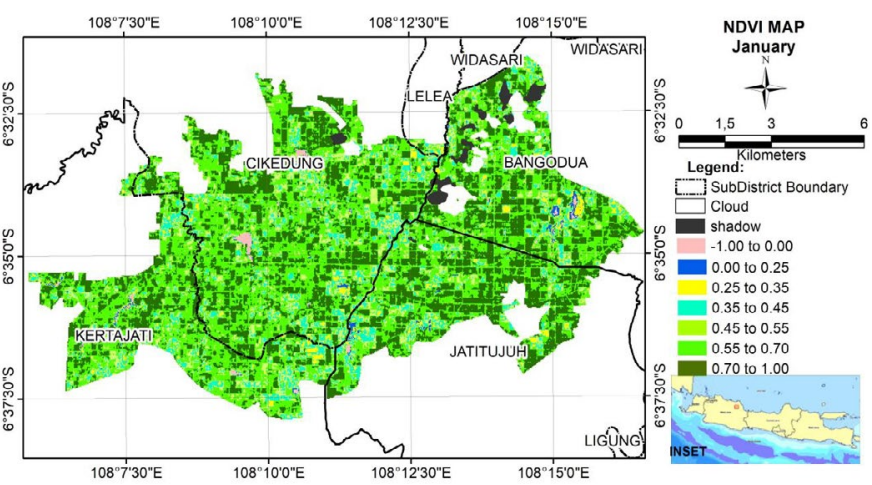

f. In January the NDVI results showed the land already planted with sugarcane and the third phase of sugarcane crop began spreading widely

Figure 3. Sugarcane growth phases based on NDVI analysis. In March the sugarcane crops are dominated by the highest NDVI value. It interpreted as the peak of the third phase. May to July, NDVI value begins to decrease. It interpreted as the fourth phase. August is dominated by low NDVI values. It interpreted as the peak of harvest. October to January NDVI value began to increase, it interpreted sugarcane crops began to grow

\section{Discussion}

Vegetation analysis indicates that in the south of oil and gas field, the sugarcane is a suspected by hydrocarbon microseepage. Hydrocarbon seepage occurs because (1) all hydrocarbon basins exhibit some type of nearsurface leakage; (2) hydrocarbon accumulations are dynamic and their seals imperfect; (3) hydrocarbon seepage can occur actively and passively and that it can be visible (macroseepage) or only detectable analytically (microseepage)(Schumacher 2001).Hydrocarbon seepage can cause the land surface vegetation to be stress (Li et al. 2012). Vegetation stress characterized by slow growth, 


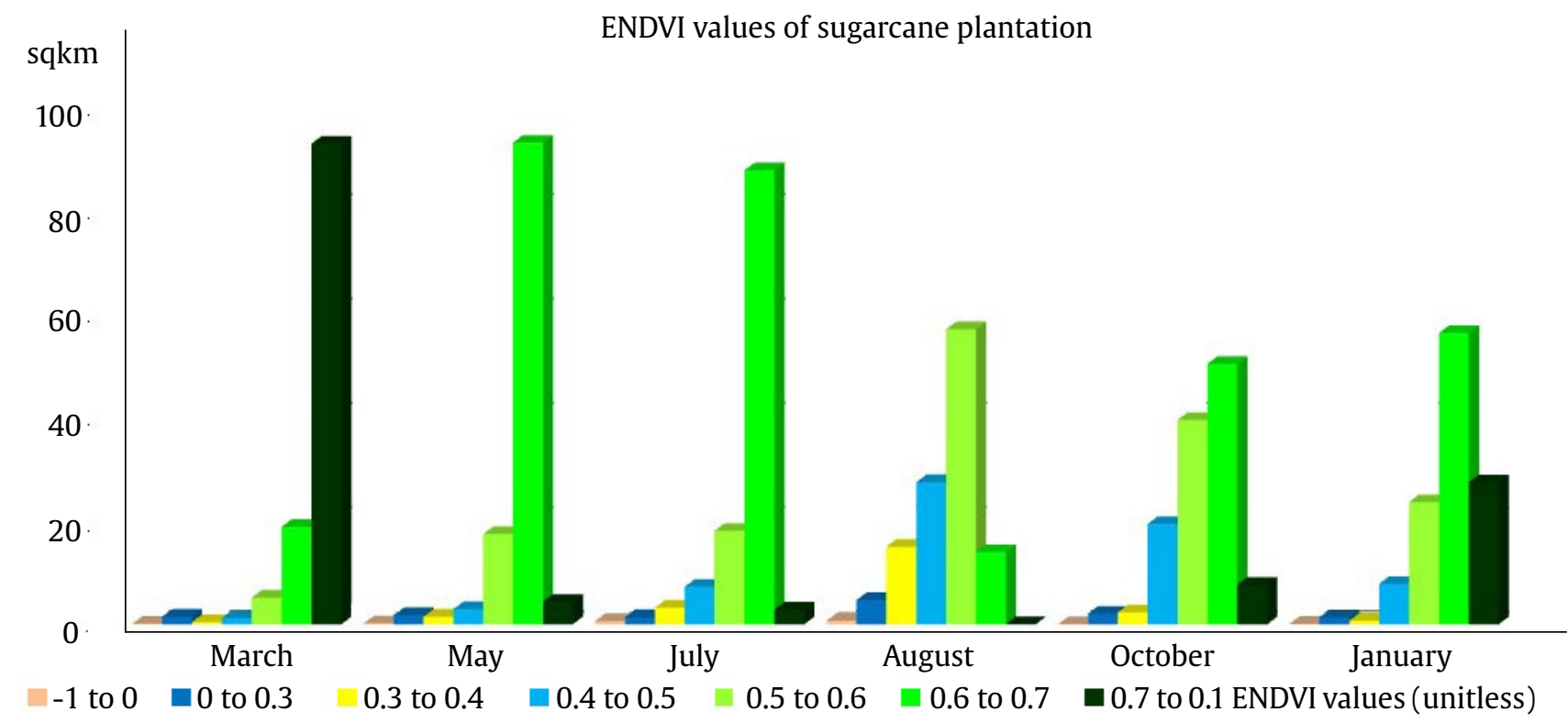

Figure 4. Chart of sugarcane area based on ENDVI values. Based on the chart can be analyzed that in March is the peak of the third phase of sugarcane crops and the peak of the harvest in August to October

reduced leaf chlorophyll (Noomen 2007; Lakkaraju et al. 2010), low vegetation density (Werff et al. 2006), leaf conditions tend to yellowish (Susantoro et al. 2017) and in the internal leaves of carotenoids is increased (Strachan et al. 2002). The previous research shows the value of vegetation index around the oil and gas wells tend to be low and increase when away from it (Susantoro et al. 2016).

The analysis of NDVI and ENDVI showed that the growth phase results of sugarcane are similar. However, the ENDVI results are more assertive to identify the harvest period. The ENDVI provide an indicator of live green vegetation and can be used for crops in all growth stages (Precisionmapper 2017). The ENDVI also can be used to assess the presence and health of crop (DroneDeploy 2017).

The growing phases from the first to the third phase as the result of NDVI and ENDVI are similar. These can be seen from the wide area of the NDVI and ENDVI values between 0 to 0.45 (Figure 6). The harvesting period analysis indicates that the low vegetation indices values are dominant after passing the peak period. This is shown in August, where the lowest value is more dominant, while the highest values of ENDVI (0.6 to 1) is only about $13.89 \mathrm{sq} \mathrm{km}$.

The field surveys in March and August shows that the results of vegetation indices especially ENDVI are conforming the field. A field survey in March shows that the sugarcane at that time was in the third phase and there was no sugarcane mill activity. August is the peak of the harvest and some area has been planting again. The comparison of the NDVI and ENDVI values as growth and harvesting phase indicators can be seen in Figure 7.

The coefficient of determination $\left(R^{2}\right)$ of the regression correlation results of 1733 samples between NDVI and ENDVI obtained $R^{2}=0.93$ in March, $R^{2}=0.94$ in May, $R^{2}=0.95$ in July, $R^{2}=0.88$ in August, $R^{2}=0.94$ in October, and $R^{2}=0.86$ in January. It means NDVI and ENDVI has a similar function to monitor the growing phase of sugarcane.

Based on the results of NDVI and ENDVI analysis, sugarcane growth patterns can be described as follows: in the germination phase, the vegetation index value is low. This condition was caused the surface spectral dominated by the soil. In the tillering phase, the vegetation index began to rise, but not significant. In the stem elongation phase along with the rapid growth of sugar cane and the development of good clumps the vegetation index value becomes high and it reaches a peak. This condition is then relatively stable. In the maturity phase, where the sugar cane starts to ripe and yellowish of leaves so that the vegetation index value becomes decreased. It has been explained by Wibowo (2013) on the growth curve of sugarcane crop in Figure 8.

The NDVI and ENDVI analysis can be utilized to monitor the growing phase of sugarcane crops. The results of NDVI and ENDVI analysis are conforming to the field data verification. The growing phase of sugarcane at the study 


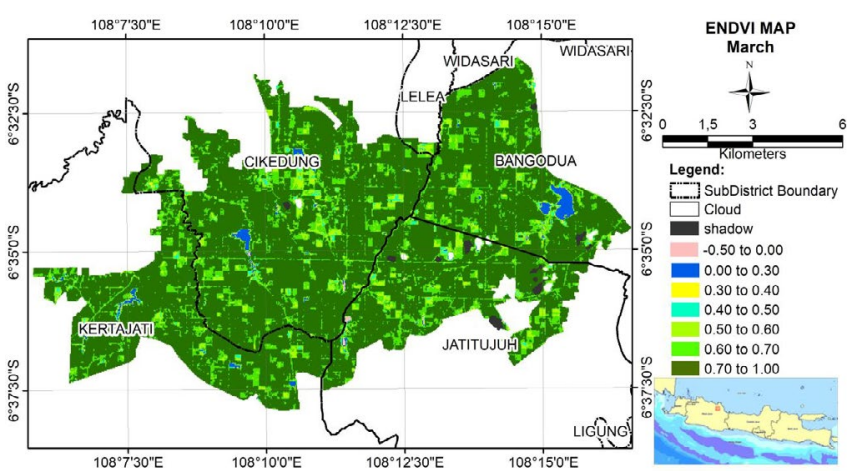

a. ENDVI results in March showed the dominant sugarcane crop in the stem elonging phase

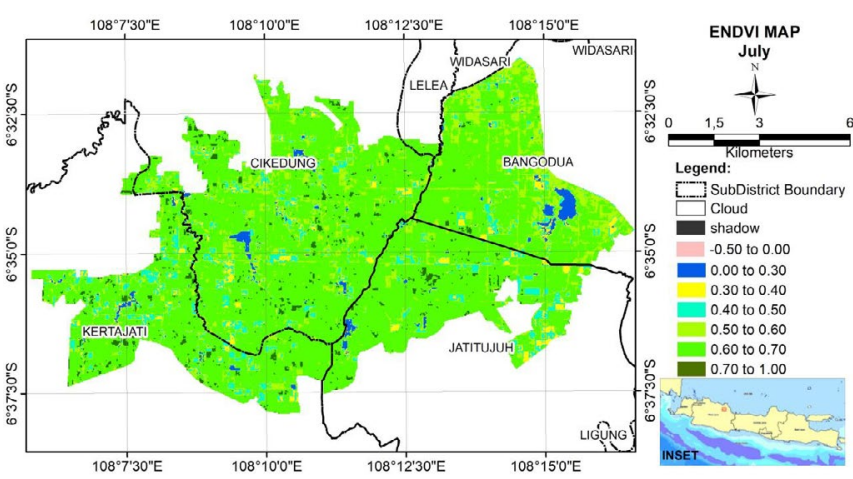

c. ENDVI results in July showed the dominant sugarcane crop in the fourth phase. The harvest has been starting in the east part

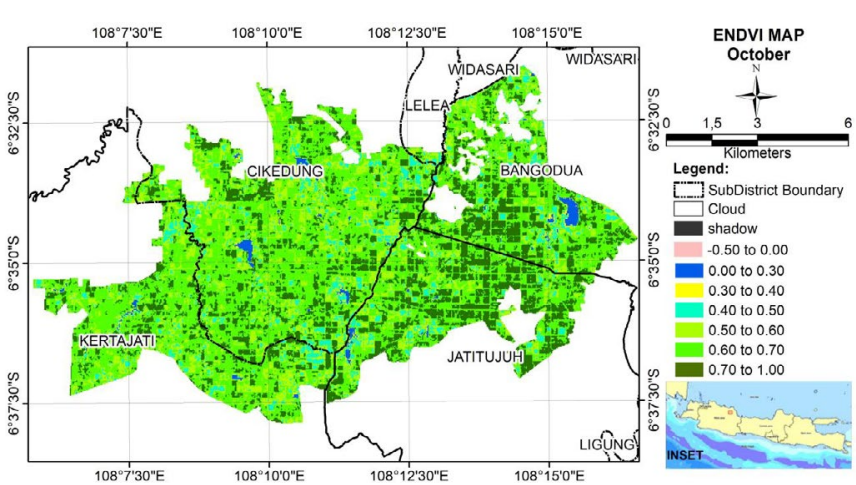

e. ENDVI results in October showed that the land has been starting to planted the sugarcane

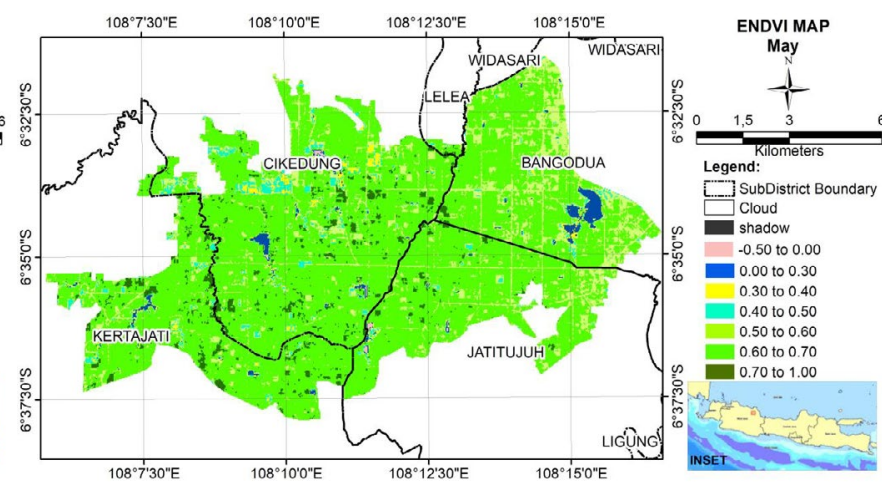

b. ENDVI results in May showed the dominant sugarcane crop in the last third phase and started to move to the fourth phase

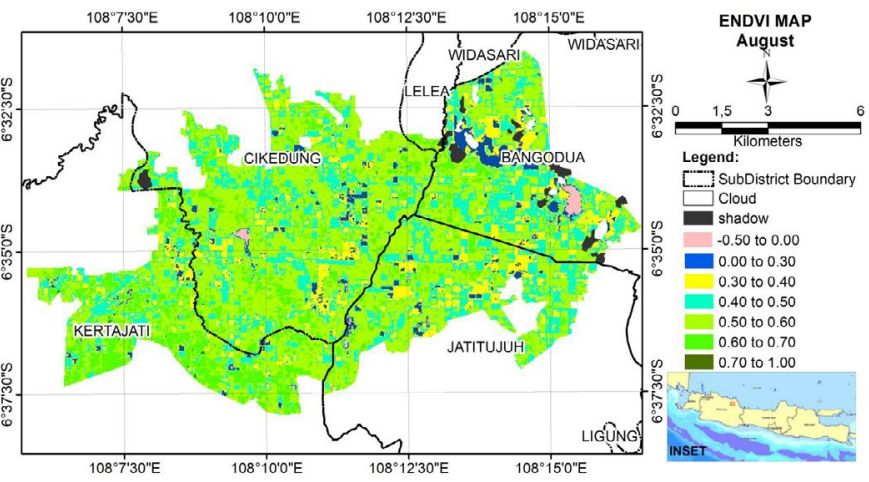

d. ENDVI results in August showed as a peak of the harvest

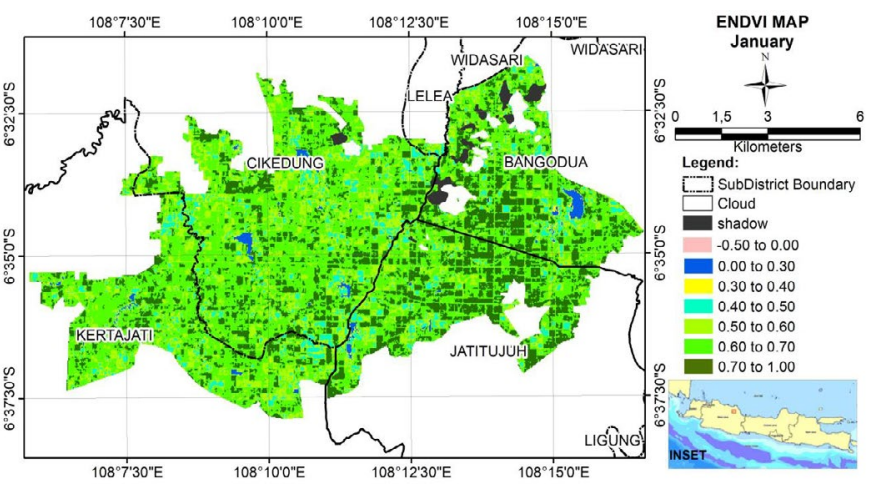

f. ENDVI results showed that the land has been growing the sugarcane and the third phase of sugarcane crop began spreading widely

Figure 5. Sugarcane growth phase based on ENDVI analysis. Similar with NDVI, in March the sugarcane crops are dominated by the highest ENDVI value. It interpreted as the peak of the third phase. May to July, ENDVI value begins to decrease. It interpreted as the fourth phase. August is dominated by low ENDVI values. It interpreted as the peak of harvest. October to January ENDVI value began to increase. It interpreted the sugarcane crops began to grow 


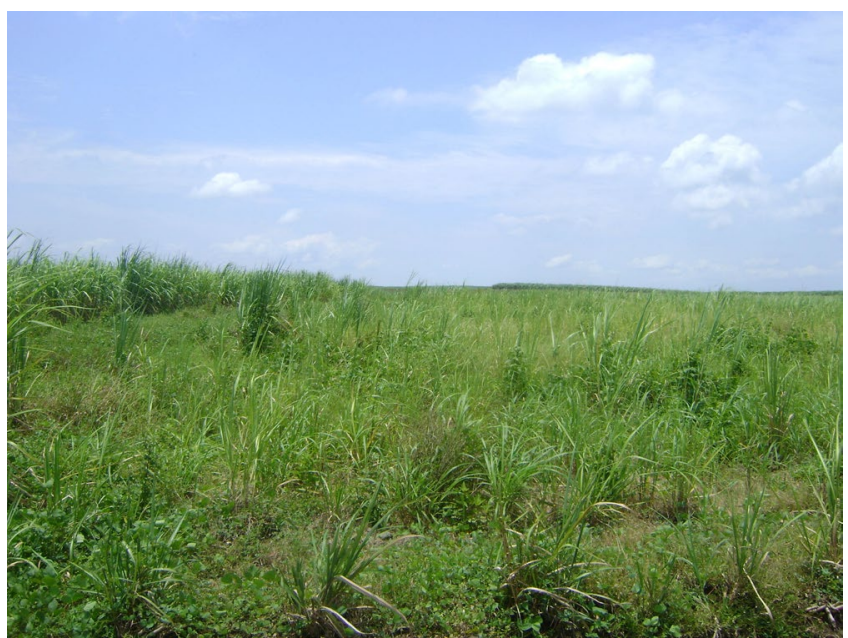

a. Sugarcane plants that do not grow well affected by hydrocarbon microseepage

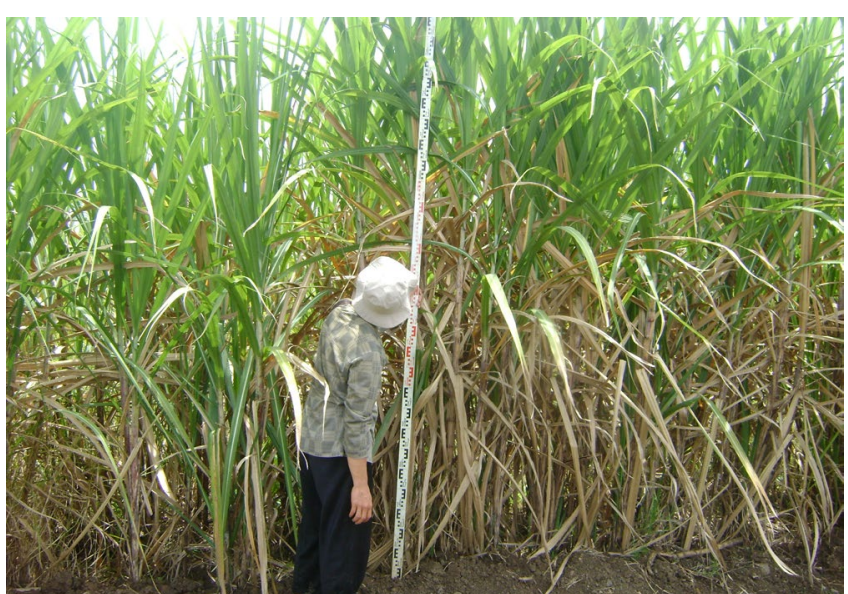

c. Sugarcane plants at stem elongation phase

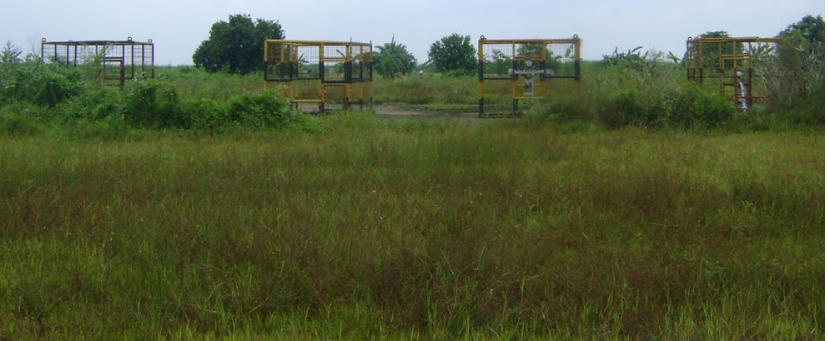

e. Oil and gas field in the middle of sugarcane plantation area

Figure 6 . The sugarcane condition

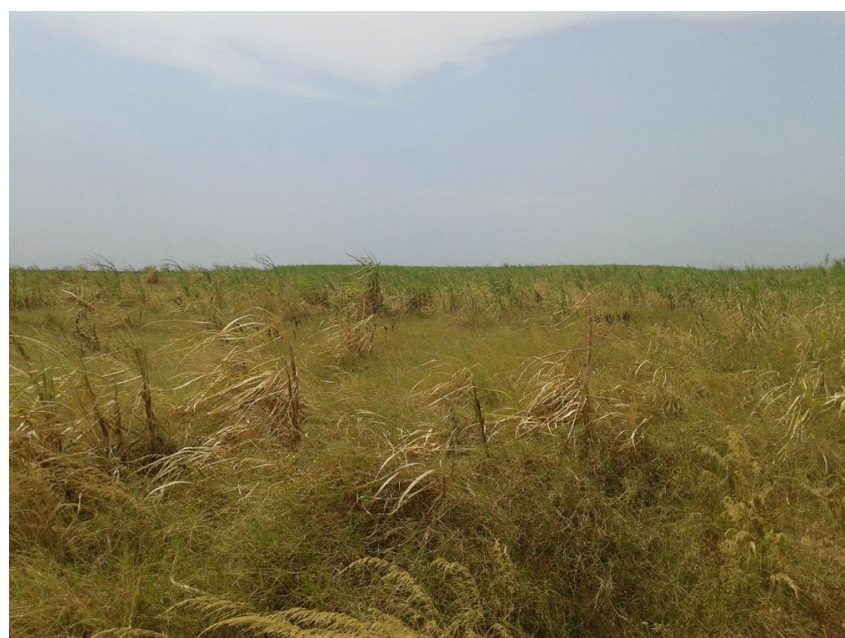

b. Sugarcane plant could not be harvested and suffered death

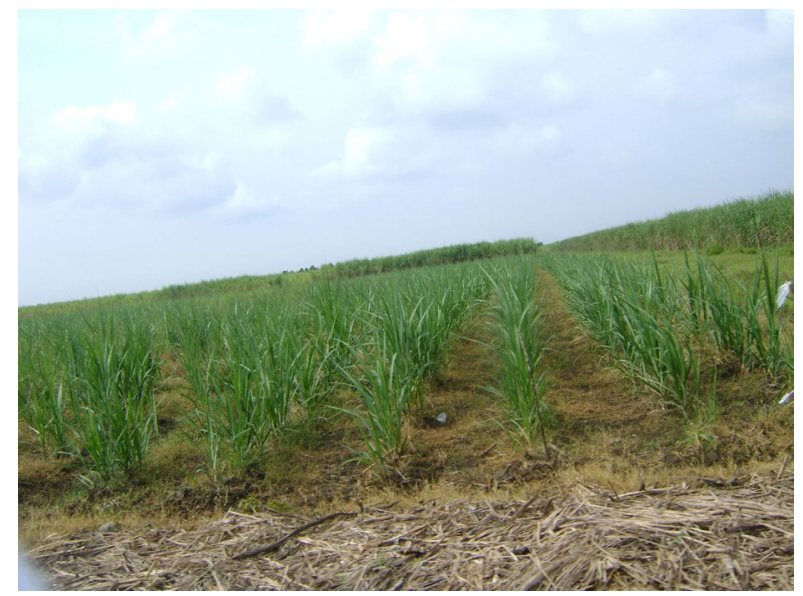

d. Sugarcane plants at tillering phase

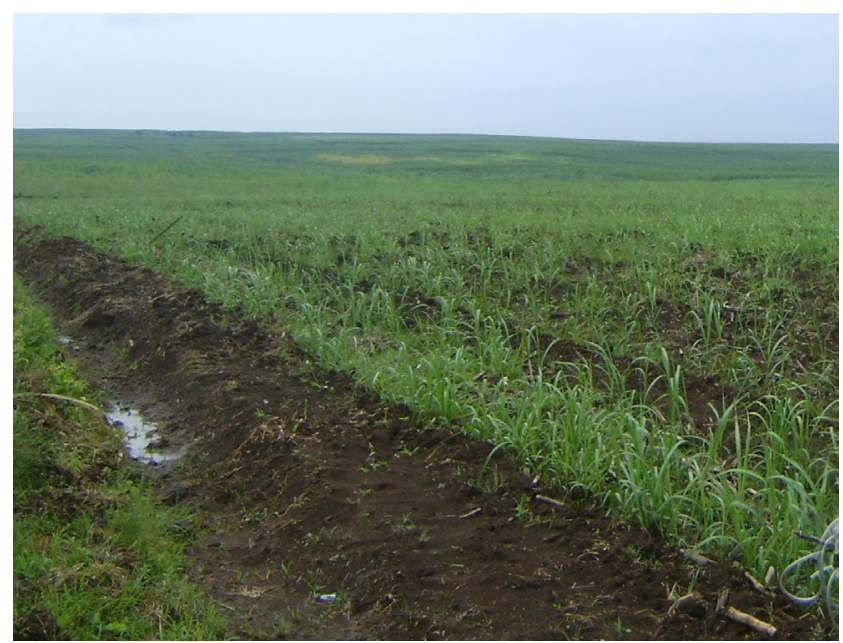

f. Sugarcane plants at germination phase 


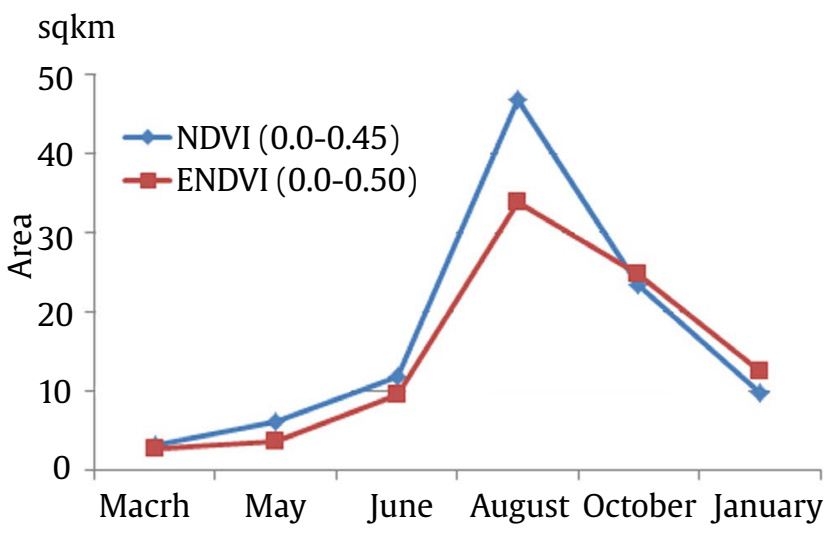

a. Chart of the area resulted from NDVI and ENDVI at low values

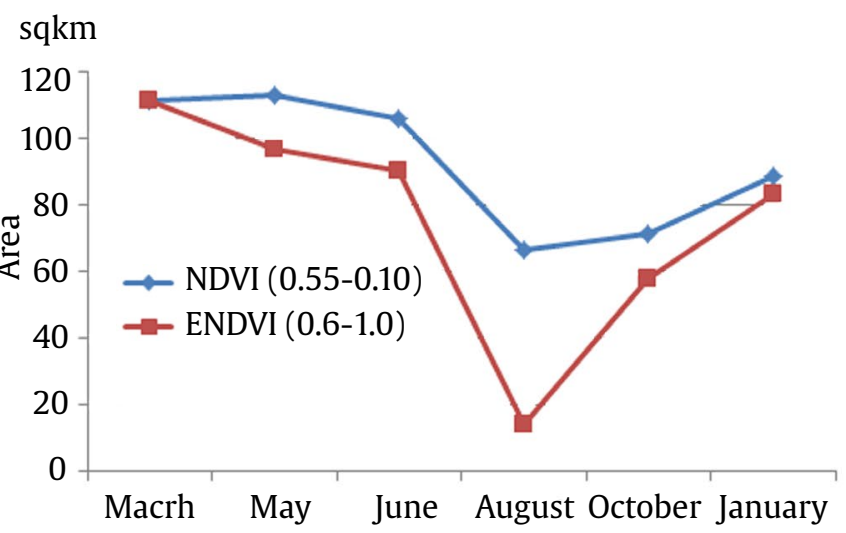

b. Chart of the area resulted from NDVI and ENDVI at high values

Figure 7. Chart of the area resulted from NDVI and ENDVI. a) low values of NDVI and ENDVI is not extremely different, it means the sugarcane crop is in the first phase to the third phase, b) the high values of NDVI and ENDVI are extreme different in August. It means in August, the sugarcane crop is at the peak of the harvest

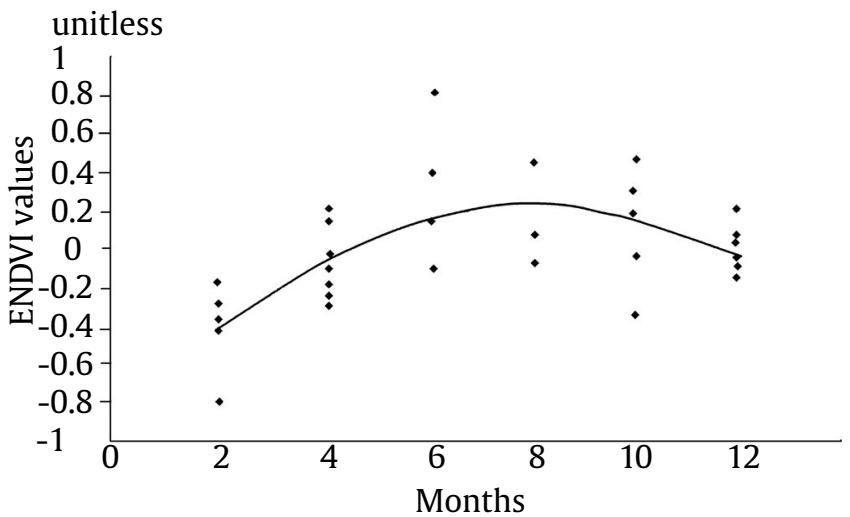

Figure 8. Growth curve of sugarcane crop based on vegetation index and plant age (Wibowo 2013)

site shows that in January the initial phase of planting has been completed and some have entered the second and third phases. March is the peak of the third phase. May and July the crops begin to enter the fourth phase and some are cut down. The peak of harvest occurs in August-October. Generally, the ENDVI results are better for monitoring the sugarcane growing phase condition than those of NDVI, especially for harvest monitoring. The model of sugarcane growth is forming a normal curve with low vegetation index value in the germination phase and then the value gradually increases to the stem elongation phase and decreases in the maturity phase. This cycle occurs continuously based on sugar cane growth stage.

\section{Conflict of Interest}

The authors declare that there is no conflict of interest.

\section{Acknowledgements}

I would like to express my deepest appreciation to all those who have provided me the opportunity to complete this paper. Special thank and appreciation are addressed to Mrs. Fithriani Agustin from Geological Survey Center, Geological Agency, Ministry of Energy and Mineral Resources and Mr. Yudhi, Mr. Heri, and Mr. Triwijaya from Research and Develompent Center for Oil and gas "LEMIGAS" Ministry of Energy and Mineral Resources for assisting the field survey.

\section{References}

Apan A et al. 2004. Detection of sugarcane 'orange rust' disease using EO-1 hyperion hyperspectral imagery. International Journal of Remote Sensing 25:489-498.

Brantley ST et al. 2011. Application of hyperspectral vegetation indices to detect variations in high leaf area index temperate shrub thicket canopies. Remote Sensing of Environment 115:514-523.

Bock M et al. 2005. Object-oriented methods for habitat mapping at multiple scales-Case studies from Northern Germany and Wye Downs, UK. Journal for Nature Conservation 13:75-89.

Chimnarong V et al. 2012. Opportunity for application of remote sensing and GIS approach for sugarcane production estimate in Thailand. In: Proceedings of the $33^{\text {rd }}$ Asian Conference on Remote Sensing. Pattaya: Asian Association on Remote Sensing. pp. 26-30.

Congalton RG. 1991. A review of assessing the accuracy of classifications of remotely sensed data. Remote Sensing of Environment 37:35-46.

Darojati NW et al. 2015. Monitoring of drought in Indramayu. Journal of Soil Environment 17:60-68. 
Danoedoro P. 2012. Introduction of Digital Remote Sensing. Yogyakarta: Publisher by Andi.

DroneDeploy. 2017. Understanding NDVI. Available at: https:// support.dronedeploy.com [Date accessed: 2 September 2017]

Fadilah R, Sumardjo. 2011. Patnership analysis between Jatitujuh sugar factory with sugarcane factory in Majalengka, West Java. Journal of Sodality: Transdisciplinary Journal of sociology, communication and human ecology 5:159172.

[FAO] Food and Agriculture Organization. 2014. Food and Agriculture Organization of the United Nations: Statistics of Crops Data. Available at: http://faostat3.fao.org/ home/E [Date accessed: 2 September 2017]

Ismoyowati D. 2004. To sustain sugar industry in Java, Indonesia: polcies on sugarcane supply and the industry's performane [Dissertation]. Yogyakarta: Indonesia: Gadjah Mada University.

Junior JZ et al. 2014. Multi-resolution in remote sensing for agricultural monitoring: a review. Revista Brasileira de Cartografia 66:1517-1529.

Khuluq AD, Hamida R. 2014. Sugarcane productivity and yield increased with sprouting physiological engineering. Perspektif 13:13-24.

Lakkaraju VR et al. 2010. Studying the vegetation response to simulated leakage of sequestered $\mathrm{CO}_{2}$ using spectral vegetation indices. Ecological Informatics 5:379-389.

Li Q et al. 2012. Study on oil and gas exploration in sparse vegetation areas by hyperspectral remote sensing data. Chinese Optic Letter 10:S11004. DOI:10.3788/ COL201210.s11004

Maxmax. 2015. Enhanced Normalized Difference Vegetation Index. Available at: https://www.maxmax.com/endvi. htm [Date accessed: 2 Febuary 2015]

Mochtar HM. 1994. Efforts to Gain Sugarcane, Fresh, and Clean (MSB). Kupat Package. Research Center for Indonesian Sugar Plantation (P3GI).

Noomen MF. 2007. Hyperspectral Reflectance of Vegetation Affected by Underground Hydrocarbon [Dissertation]. Enschede, Belanda: The Netherlands (ITC).

Obando EB et al. 2017. Estimation of transpiration fluxes from rainfed and irrigted sugarcane in South Africa using canopy resistance and crop cefficient model. Agricultural Water Management 181:94-107.

Pereira RM, Casaroli D. 2016. Sugarcane leaf area estimate obtained from teh corrected Normalized Difference Vegetation Index (NDVI). Pesq Agropec Trop Goiania 46:140-148.

Pertamina. 1994. Proposed Exploitation wells drilled. Activities Plan 1995/1996. Production Geology. Pertamina Unit EP III. Jakarta.

Pongpat P et al. 2017. An assessment of harvesting practices of sugarcane in the central region of Thailand. Journal of Cleaner Production 142:1138-1147.

Pramuhadi G. 2009. Farming mechanization of sugarcane cultivation in dryland. Food Journal 55:60-65.

Pramuhadi G. 2010. Climate factor at sugarcane culture at dryland. Food Journal 19:331-344.
Precisionmapper. 2017. Enhanced Normalized Difference Vegetation Index. Available at: https://www. precisionmapper.com/algorithms/enhancednormalized-difference-vegetation-index [Date accessed: 2 September 2017]

Rahmad D. 2012. Growth morphological characteristics of several sugarcane varieties. Journal Agroplantae $1: 121-131$.

Rahman MR et al. 2004. NDVI derived sugarcane area identification and crop condition assessment. Planplus 2:1-12.

Roberts DA et al. 2011. Hyperspectral vegetation indices (Chapter 14). In: Thenkabail PS, JG Lyon, and A Huete (eds.). Hyperspectral Remote Sensing of Vegetation. Boca Raton: CRC Press. pp. 1-35. DOI:10.1201/b11222-20.

Rouse J et al. 1974. Monitoring vegetation systems in the great plains with ERTS. In: Proceeding the Third Earth Resources Technology Satellite-1 Symposium. Vol I: Technical Presentations. NASASP-351, Compiled and Edited by Stanley C. Freden, Enrico P. Mercanti, and Margaret A. Becker, 1994 pages. Washington DC: Published by NASA. pp. 309-317.

Rudorff BFT et al. 2010. Studies on the rapid expansion of sugarcane for etanol production in São Paulo state (Brazil) using Landsat data. Remote Sensing 2:1057-1076.

Salas EAL, Henebry GM. 2014. A New approach for the analysisi of hyperspectral data: theory and sensitivity analysis of the moment distance method. Remote Sensing 6:20-41.

Schumacher D. 2001. Petroleum exploration in environmentally sensitive areas: opportunities for non-invasive geochemical and remote sensing methods. In: Proceedings of the Rock the Foundation Convention. Calgary: Canadian Society of Petroleum Geologist. pp. 18-22.

Silalertruksa T et al. 2017. Life cycle assessment for enhancing envrionmental sustainability of usgarcane biorefinery in Thailand. Journal of Cleaner Production 140:903-913.

Simoes MDS et al. 2005. Spectral variables, growth analysis, and yield of sugarcane. Scientia Agricola 62:199-207.

Strachan IB et al. 2002. Impact of nitrogen and environmental conditions on corn as detected by hyperspectral reflectance. Remote Sensing of Environment 80:213-224.

Suhardi S et al. 1999. Designing of furrow irrigation system in sugarcane plantation with hydrodynamics model. Agrosains 12:1-7.

Susantoro TM et al. 2016. Impact of oil and gas gield in sugarcane condition using Landsat 8 in Indramayu area and its surrounding, West Java Province, Republic of Indonesia. In: Proceeding of the $3^{\text {rd }}$ International Symposium on LAPAN-IPB Satellite for Food Security and Environmental Monitoring. Bogor: Published in IOP Conference Series: Earth and Environmental Science 54 (2017) 012019. pp. 1-10.

Susantoro TM et al. 2017. Utilization of vegetation indices to interpret the possibility of oil and gas microseepages at ground surface. Paper Presented at the $1^{\text {st }}$ UPI International Geography Seminar. Bandung-Indonesia. 
Tucker CJ et al. 1985. African land-cover classification using satellite data. Science 227:369-375.

Werff HMAVD et al. 2006. Remote sensing of onshore hydrocarbon Seepage: problems and solutions. Geological Society London Special Publication 283:125133.

Wibowo JTP. 2013. Utilization of near infrared cameras by unmanned aerial vehicle for monitoring the maturity level of sugarcane plant [Tesis]. Bandung, Indonesia: Bandung Institute of Technology.
Xavier AC et al. 2006. Multi-temporal analysis of MODIS data to classify sugarcane crop. Int J Remote Sens 27:755-768. Zhou Z et al. 2015. Object-oriented classification of sugarcane using time-series middle-resolution remote sensing data based on AdaBoost. PLoS ONE 10:1-16. DOI:10.1371 /journal.pone.0142069 